\title{
Atezolizumab Regimen
}

National Cancer Institute

\section{Source}

National Cancer Institute. Atezolizumab Regimen. NCI Thesaurus. Code C159992.

An immunotherapy regimen consisting of atezolizumab that may be used in the treatment of bladder, breast and non-small cell lung cancers. 